Article

\title{
Ancient Tomato (Solanum lycopersicum L.) Varieties of Tuscany Have High Contents of Bioactive Compounds
}

\author{
Roberto Berni ${ }^{1,2}{ }^{(1)}$, Marco Romi ${ }^{1}$, Luigi Parrotta ${ }^{1,3}$, Giampiero Cai ${ }^{1}$ (i) and Claudio Cantini ${ }^{2, *}$ (I) \\ 1 Department of Life Sciences, University of Siena, via P.A. Mattioli 4, 53100 Siena, Italy; \\ berni10@student.unisi.it (R.B.); marco.romi@unisi.it (M.R.); parrotta2@unisi.it (L.P.); \\ giampiero.cai@unisi.it (G.C.) \\ 2 Trees and Timber Institute-National Research Council of Italy (CNR-IVALSA), via Aurelia 49, \\ 58022 Follonica, Italy \\ 3 Department of Biological, Geological and Environmental Sciences, University of Bologna, via Irnerio 42, \\ 40126 Bologna, Italy \\ * Correspondence: cantini@ivalsa.cnr.it
}

Received: 23 October 2018; Accepted: 27 November 2018; Published: 30 November 2018

\begin{abstract}
The Tuscan Region has a vast repertoire of ancient plants that have been recovered across the territory over the years. These plants thrive in an environment characterized by minimal human intervention and are thus the result of the process of adaptation to the territory of origin. In this work, we focused on the quantification of bioactive compounds in ancient tomato varieties. More specifically, we quantified polyphenols, flavonoids, carotenoids, and vitamin $C$ in eight local Tuscan tomato varieties and found higher contents with respect to those in commercial tomatoes Polyphenol and antioxidant compounds in ancient varieties reported a two- and, in some instances, three-fold increase in concentration, compared to the commercial counterparts. Interestingly, the data relative to the carotenoids did not show any significant differences when comparing the ancient varieties with the commercial ones, a finding confirming the market selection criterion based on color. On a longer-term perspective, this study aims at drawing attention to the importance of preserving autochthonous natural plant biodiversity and towards promoting research on local varieties. We believe that this study will pave the way to the valorization of local plant biodiversity and promote an extended use of products in the nutraceutical sector derived from vegetables.
\end{abstract}

Keywords: local crops; nutraceuticals; agricultural biodiversity; anti-oxidants

\section{Introduction}

According to the most recent scientific definition, the optimal diet consists not only of energy compounds but also of so-called "functional" compounds that are able to improve human health. Foods containing these beneficial compounds are referred to as "nutraceuticals" and are defined as "food, or any food, which provides medical or health benefits, including disease prevention and treatment" [1]. Most of these functional compounds derive from the secondary metabolism of plants and are synthesized in response to (a) biotic stresses, as well as during normal physiological processes (e.g., lignin biosynthesis during secondary cell wall formation) [2]. Plant secondary metabolites display bioactivity and can thus be useful for humans, in the form supplements, if included in the diet [3,4].

In recent years, the science of nutrition has been moving away from the concept of adequate nutrition to optimal nutrition, with the aim of promoting the consumption of foods that contribute to improving psycho-physical health and reducing the risk of disease. The focus is mainly on foods of plant origin because they contain a considerable amount of antioxidant compounds, such as phenols 
and carotenoids. Numerous studies have shown the activity of these compounds against free radicals which are responsible for oxidative stress. Polyphenols and carotenoids are secondary plant metabolites that play important roles in many physiological aspects of plants, such as growth, plant protection, intracellular signaling, and pigmentation [5]. However, complex processes, such as absorption and metabolism, combined with evidence of actual circulating concentrations of polyphenols and metabolites, suggest that a regular diet does not always provide adequate amounts of compounds to ensure protective effects [6]. Increasing the intake of positive antioxidants might be possible by consuming foods containing higher levels of these compounds [7].

Phenolic compounds represent the most abundant antioxidants in the human diet and have been found in different types of plant-derived foods, such as fruit, cereals, pulses, and chocolate, and in beverages such as tea, coffee, or wine. Fruits contain a large amount of antioxidant compounds, for example up to 200-300 mg of polyphenols and carotenoids per $100 \mathrm{~g}$ fresh weight [8]. About 8000 different compounds have been described from scientific reports characterized by a basic chemical structure containing aromatic rings that form bonds with one or more hydroxyl groups. Their classification is based on the number and arrangement of these phenolic rings and other structural elements allowing the formation of four subclasses of compounds: phenolic acids; flavonoids, which include flavonols, flavones, isoflavones, flavanones, anthocyanidins, and flavanols; stilbenes; and lignans [9].

Another important antioxidant involved in the defense against oxidation is lycopene, a compound of the carotenoid class. Lycopene is a natural pigment synthesized by microorganisms and plants, but not by animals [10]. In humans, lycopene can be consumed from fruits and vegetables through the daily diet, and its permanence in the blood is influenced by different biological factors such as lifestyles [11]. Its production level is affected by different within-plant biological factors. Tomato is one of the most widespread and consumed agricultural products in the world; it is extensively cultivated under different conditions such as fields, greenhouses, or small home gardens.

Tomatoes have a high nutritional value and contain a wide variety of natural antioxidants, such as carotenoids, vitamin C, and phenolic compounds [12]. The growing interest in tomato polyphenols is related to their antioxidant properties and possible health benefits. The content of antioxidant compounds in tomato fruit can protect human cellular components from oxidative damage and thus limit the risk of degenerative diseases associated with oxidative stress [13]. Evidence in animal models has shown that antioxidants, if combined with the normal diet, limit the development of diseases, such as tumors, cardiovascular, and neurodegenerative disorders [14].

A strong body of evidence in the literature has shown that increasing tomato consumption in the diet may lead to a $50 \%$ reduction in risk of cardiovascular disease and an $83 \%$ reduction in the risk of prostate cancer [15]. Because of the presence of these compounds, the tomato has a high nutraceutical value and can be considered as a functional food with positive effects in various pathological disorders [16].

Tomatoes are an important heritage of Tuscan biodiversity and show a high capacity/plasticity to react and adapt to environmental changes [17]. Environmental factors have led these varieties to develop molecular strategies of adaptation to the territory that have resulted, with time, in an increased content of defense compounds [18]. Studies have shown that local varieties of cultivated plants thriving in an environment with minimal human impact have a higher content of beneficial compounds than commercial ones [19]. Therefore, autochthonous fruit crops are an alternative source of compounds that are beneficial to human health, as well as being important for the valorization of the local agriculture and biodiversity [20]. The cultivation of tomatoes in restricted areas led, through the centuries, to the selection of local "autochthonous" varieties adapted to the environment. These varieties are an important source of genetic variability and contribute substantially to local biodiversity [20].

A study of tomato biodiversity within the Tuscany Region showed the presence of eight distinct varieties: 'Liscio da Serbo Toscano', 'Rosso di Pitigliano', 'Quarantino ecotipo (ec.) Valdarno', 'Fragola', 'Canestrino di Lucca', 'Costoluto fiorentino', 'Giallo di Pitigliano', and 'Pisanello'. These local genotypes 
have been described, put in collection for conservation, and included in a regional genetic database (http:/ / germoplasma.regione.toscana.it/) [20]. So far, no information is available on the content of bioactive compounds of these local ancient varieties.

The aim of this work was to quantify the antioxidant compounds in eight ancient Tuscan tomato varieties compared to three commercial ones. The quantification of polyphenols, carotenoids, flavonoids, and vitamin C will contribute to: (1) promoting the full exploitation of the antioxidant potential of these tomatoes, (2) increasing their cultivation and consumption and (3) selecting the varieties to be used as genetic resources in future breeding programs.

\section{Materials and Methods}

\subsection{Fruit Sampling}

The seeds of eight local ancient Tuscan varieties included in the Regional Genetic Repertory, namely 'Liscio da Serbo Toscano', ‘Rosso di Pitigliano', 'Quarantino ecotipo (ec.) Valdarno', 'Fragola', 'Canestrino di Lucca', 'Costoluto fiorentino', 'Giallo di Pitigliano', and 'Pisanello', were obtained from the Tuscan Seed Bank of Tuscany. The seeds were germinated together with three commercial varieties found on the market, i.e., 'Insalataro', 'San Marzano', and 'Cuore di Bue'. The plants were produced by the Santa Paolina experimental farm of the National Research Council of Italy (CNR IVALSA) located in Follonica (Italy) $\left(42^{\circ} 55^{\prime} 59.7^{\prime \prime} \mathrm{N} 10^{\circ} 45^{\prime} 53.0^{\prime \prime} \mathrm{E}\right)$ and then cultivated under traditional agronomic conditions. Harvesting of the fruits was performed at the same ripeness level (between $30-40$ days after anthesis) during the period from 1 July to 15 September 2016 . Fruits were immediately placed at $-80^{\circ} \mathrm{C}$ to block any metabolic process. This work forms a part of a study investigating the content of functional compounds in ancient Tuscan tomato varieties harvested in consecutive years (2016-2017-2018).

\subsection{Sample Extraction}

The extraction procedure was conducted as previously described by [21]. A total of $9.0 \mathrm{~mL}$ of $70 \%$ acetone was added to $3 \mathrm{~g}$ of frozen fruits and then homogenized using an Ultra-Turrax ${ }^{\circledR} \mathrm{T}-25$ basic (IKA ${ }^{\circledR}$-Werke GmbH \& Co., IKA, Staufen, Germany). The mixture was then sonicated for 20 min with an Elma Transsonic $\mathrm{T} 460 / \mathrm{H}$ and homogenized once again to achieve total lysis of the plant material. The final mixture was centrifuged for $5 \mathrm{~min}$ at 12,000 rpm (Microcentrifuge 5415D, Eppendorf ${ }^{\circledR}$, Hamburg, Germany) and finally filtered through a $0.45 \mu \mathrm{m}$ membrane filter to limit sample impurities.

\subsection{Evaluation of Antioxidant Capacity}

The Ferric Reducing Antioxidant Power (FRAP) assay, used in both animal and plant studies [22], was determined for each extract. The FRAP reagent was freshly prepared and it consisted of $2040 \mu \mathrm{L}$ of sodium acetate buffer ( $300 \mathrm{mM} \mathrm{pH}$ 3.6) mixed with $200 \mu \mathrm{L}$ of $10 \mathrm{mM}$ TPTZ (2,4,6-tripyridyl-s-triazine) and $200 \mu \mathrm{L}$ of $20 \mathrm{mM}$ ferric chloride. In the last step, $20 \mu \mathrm{L}$ of sample extract was added to the solution, and then the solution was incubated for $1 \mathrm{~h}$ at $37^{\circ} \mathrm{C}$. FRAP values were obtained by comparing the absorbance change at $593 \mathrm{~nm}$ in test reaction mixtures with a ferric chloride standard curve previously prepared by UV-Vis spectrophotometer (Shimadzu UV Visible Recording Spectrophotometer UV 160, Shimadzu, Kyoto, Japan). The values were expressed in mmol of ferrous chloride $\left(\mathrm{Fe}^{2+}\right)$ equivalents per $100 \mathrm{~g}$ fresh weight (FW).

\subsection{Evaluation of the Phenolic Content}

The phenolic content was evaluated using the Folin-Ciocalteau $(\mathrm{F}-\mathrm{C})$ method which is used as a standardized method for routine analysis of a food product. The method uses a mixture of phosphomolybdic acid and phosphotungstic acid allowing electron transfer in an alkaline medium. Phenolic compounds form blue complexes that are quantified spectrophotometrically at $765 \mathrm{~nm}$ [23]. For our quantifications, $500 \mu \mathrm{L}$ of a sample extract was added to $3.0 \mathrm{~mL}$ of distilled water and $250 \mu \mathrm{L}$ 
of F-C reagent (Sigma Chemical, St. Louis, MI, USA). Then, $750 \mu \mathrm{L}$ of saturated sodium carbonate and $950 \mu \mathrm{L}$ of distilled water were added. The mixture was incubated for $30 \mathrm{~min}$ at $37^{\circ} \mathrm{C}$; at the end, the absorbance was recorded at $765 \mathrm{~nm}$. The spectrophotometric results were compared to a pre-made gallic acid standard (Sigma Chemical, St. Louis, MI, USA) curve. The total phenolic content was expressed as milligrams of gallic acid equivalents (GAE) per $100 \mathrm{~g}$ fresh weight.

\subsection{Evaluation of Flavonoid Content}

The aluminum chloride method allows the determination of the total flavonoid content, separating their contribution from that of polyphenols. The principle is that aluminum chloride can form complexes with flavonoids in an acidic medium [24]. Briefly, $500 \mu \mathrm{L}$ solutions of each fruit extract were mixed with $1.5 \mathrm{~mL}$ of methanol, $100 \mu \mathrm{L}$ of $10 \%$ aluminum chloride, $100 \mu \mathrm{L}$ of $1 \mathrm{M}$ potassium acetate, and $2.8 \mathrm{~mL}$ of distilled water. After incubating at room temperature for $30 \mathrm{~min}$, the absorbance of the solutions was measured at $415 \mathrm{~nm}$ (Shimadzu UV Visible Recording Spectrophotometer UV 160, Shimadzu, Kyoto, Japan). The total flavonoid content was calculated in relation to a quercetin standard (Sigma Chemical, St. Louis, MI, USA) from a calibration curve and the values were expressed as milligrams of quercetin equivalents (QeE) per $100 \mathrm{~g}$ of fruit.

\subsection{Evaluation of Carotenoid Content}

The carotenoid content was evaluated as previously described [25] and modified for our analysis. The method consists of the extraction of carotenoid compounds and evaluation by spectrophotometric analysis. Three grams of fresh fruits were added to $3 \mathrm{~mL}$ of extraction solvent composed of methanol, acetone, hexane (50:25:25), mixed for $5 \mathrm{~min}$, then sonicated for $20 \mathrm{~min}$. The mixture was centrifuged for $5 \mathrm{~min}$ at 12,000 rpm and the supernatant was recovered. The sample was evaporated by rotary evaporation at $30^{\circ} \mathrm{C}$ for $3-5 \mathrm{~min}$ and then diluted in $3 \mathrm{~mL}$ of $100 \%$ acetone. To calculate the carotenoid content, we used 3 different wavelengths and applied the following mathematical formulae [25]:

$$
\begin{gathered}
C a=11.75 \mathrm{~A}_{662}-2.35 \mathrm{~A}_{645}, \\
C b=18.61 \mathrm{~A}_{645}-3.96 \mathrm{~A}_{662} \\
C x+c=\left(1000 \mathrm{~A}_{470}-2.27 C a-81.4 C b\right) / 227
\end{gathered}
$$

$C a$ is the individual levels of chlorophyll $a, C b$ is the level of chlorophyll $b$, and $C x+c$ is the total carotenoid content (TCC). A is the value that refers to the sample readings at different wavelengths.

\subsection{Extraction of Polyphenols and HPLC Determination}

Approximately $5 \mathrm{~g}$ of fruit tissue was dissolved in $5 \mathrm{~mL}$ of acidified methanol $(5 \mathrm{~mL})$ containing $1 \%$ $(v / v) \mathrm{HCl}$. The standard procedure used for acid hydrolysis of the flavonoid components was analyzed as described for quercetin, myricetin, and kaempferol in tomatoes and processed products [26]. The mixture was incubated at $90{ }^{\circ} \mathrm{C}$ for $2 \mathrm{~h}$ and continuously stirred. The sample was cooled to room temperature and sonicated for $3 \mathrm{~min}$ to remove oxygen before injection. The final extract was filtered through a $0.45 \mu \mathrm{m}$ membrane filter. The HPLC method was adapted to our study based on Kumar [27]. The analysis was carried out with an RP-C18 column (SUPELCO Kromasil 100A-5u-C18 $4.6 \mathrm{~mm} \times 250 \mathrm{~mm}$ ), at a flow rate $1 \mathrm{~mL} / \mathrm{min}$ and the absorbance set at $280 \mathrm{~nm}$, in a run time of $21 \mathrm{~min}$. The mobile phase consisted of two solutions, A) $\mathrm{H}_{2} \mathrm{O}$ and B) acetonitrile with $0.02 \%$ trifluoroacetic acid, and the following gradient: 0-5 min A (20\%)-B (80\%); 5-8 min A (60\%)-B (40\%); 8-12 min A (50\%)-B (50\%); $12-17$ min A (60\%)-B (40\%); 17-21 min A $(80 \%)-B(20 \%)$. Quantification was performed using an external standard calibration curve consisting of six points at the increasing concentrations of $0.5,2$, $5,12,25$, and $50 \mu \mathrm{g}$ per $\mathrm{mL}$ for the standards caffeic acid, ferulic acid, chlorogenic acid, quercetin, and naringenin (Sigma Chemical, St. Louis, MI, USA). 


\subsection{Extraction of Lycopene and HPLC Determination}

A total of $3 \mathrm{~g}$ of fruit material was mixed in $100 \mathrm{~mL}$ of solvent solution hexane/acetone/ethanol (50:25:25 v/v/v). The mixture was magnetically stirred for $30 \mathrm{~min}$. Then, $15 \mathrm{~mL}$ of water was added and an aliquot of $10 \mathrm{~mL}$ of the extract was evaporated to dryness. The residue was dissolved to a final volume of $4 \mathrm{~mL}$ of tetrahydrofuran (THF)/methanol/water solution. The final solution was filtered through a $0.45 \mu \mathrm{m}$ membrane filter and $20 \mu \mathrm{L}$ were used for HPLC analysis. The mobile phase was composed of methanol/acetone $(90 / 10 v / v)$ and $9 \mu \mathrm{M}$ triethanolamine at a flow rate of $0.9 \mathrm{~mL} / \mathrm{min}$. An RP-C18 column (SUPELCO Kromasil 100A-5u-C18 $4.6 \mathrm{~mm} \times 250 \mathrm{~mm}$ ) was used, and the temperature was set at $30^{\circ} \mathrm{C}$, while the absorbance was set at $475 \mathrm{~nm}$. The analysis was performed during $15 \mathrm{~min}$ under isocratic conditions of the mobile phase [28]. Quantification was performed using an external standard calibration curve, consisting of six points at the increasing concentrations of $0.5,2$, $5,12,25$, and $50 \mu \mathrm{g}$ per mL for a lycopene standard (Sigma Chemical, St. Louis, MI, USA).

\subsection{Extraction of Vitamin C and HPLC Determination}

Ascorbic acid was extracted directly from homogenized fruits. Plant material ( $3 \mathrm{~g})$ was mixed with $3 \mathrm{~mL}$ of milli-Q water, then filtered through a $0.45 \mu \mathrm{m}$ membrane filter and $20 \mu \mathrm{L}$ were taken from the flow-through for HPLC (PerkinElmer Series 200 HPLC Systems) [29]. An RP-C18 column (SUPELCO Kromasil 100A-5u-C18 $4.6 \mathrm{~mm} \times 250 \mathrm{~mm}$ ) and a diode array detector (PerkinElmer Inc. Series 200 Diode Array Detector, PerkinElmer, Norwalk, CT, USA) were used. The mobile phase consisted of a $0.01 \mathrm{M} \mathrm{KH}_{2} \mathrm{PO}_{4}$ buffered at $\mathrm{pH} 2.6$ with o-phosphoric acid. An isocratic elution with a flow rate of $0.5 \mathrm{~mL} / \mathrm{min}$ was used and detection was carried out at $250 \mathrm{~nm}$. Quantification was carried out using an external standard calibration curve, consisting of six points at increasing concentrations of $0.5,2.5$, $5,12,25$, and $50 \mu \mathrm{g}$ per $\mathrm{mL}$ for a vitamin $\mathrm{C}$ standard.

\subsection{Statistical Analysis}

For each extract, three analytical measurements were made for each parameter and a final value was calculated as an average for each sample. Three independent biological replicates were obtained from each genotype and reported using the standard deviation (SD). The data were analyzed by a one-way analysis of variance (ANOVA) and the difference was considered significant when the $P$-value was $<0.05$.

\section{Results}

\subsection{Antioxidant Capacity}

Results showed that the antioxidant capacity of ancient tomatoes ranged from a minimum of $0.39 \mathrm{mmol} \mathrm{Fe} \mathrm{F}^{2+} / 100 \mathrm{~g} \mathrm{FW}$ in the 'Pisanello' variety, to a maximum of $0.84 \mathrm{mmol} \mathrm{Fe}{ }^{2+} / 100 \mathrm{~g}$ FW in the 'Rosso di Pitigliano' variety (Figure 1). The highest concentrations of antioxidants were in 'Rosso di Pitigliano' and 'Liscio da Serbo Toscano', while a high value was also obtained for 'Quarantino ec. Valdarno' (0.74 mmol Fe $\left.{ }^{2+} / 100 \mathrm{~g} \mathrm{FW}\right)$. 'Fragola' and 'Giallo di Pitigliano', on the other hand, showed the lowest values among local varieties ( 0.45 and $0.41 \mathrm{mmol} \mathrm{Fe}^{2+} / 100 \mathrm{~g} \mathrm{FW}$, respectively). The commercial tomato varieties were the lowest compared to all the ancient tomato varieties studied with values of $0.25 \mathrm{mmol} \mathrm{Fe}{ }^{2+} / 100 \mathrm{~g}$ FW for 'Insalataro', $0.31 \mathrm{mmol} \mathrm{Fe}{ }^{2+} / 100 \mathrm{~g}$ FW for San Marzano and $0.29 \mathrm{mmol} \mathrm{Fe}^{2+} / 100 \mathrm{~g}$ FW for 'Cuore di Bue'. 


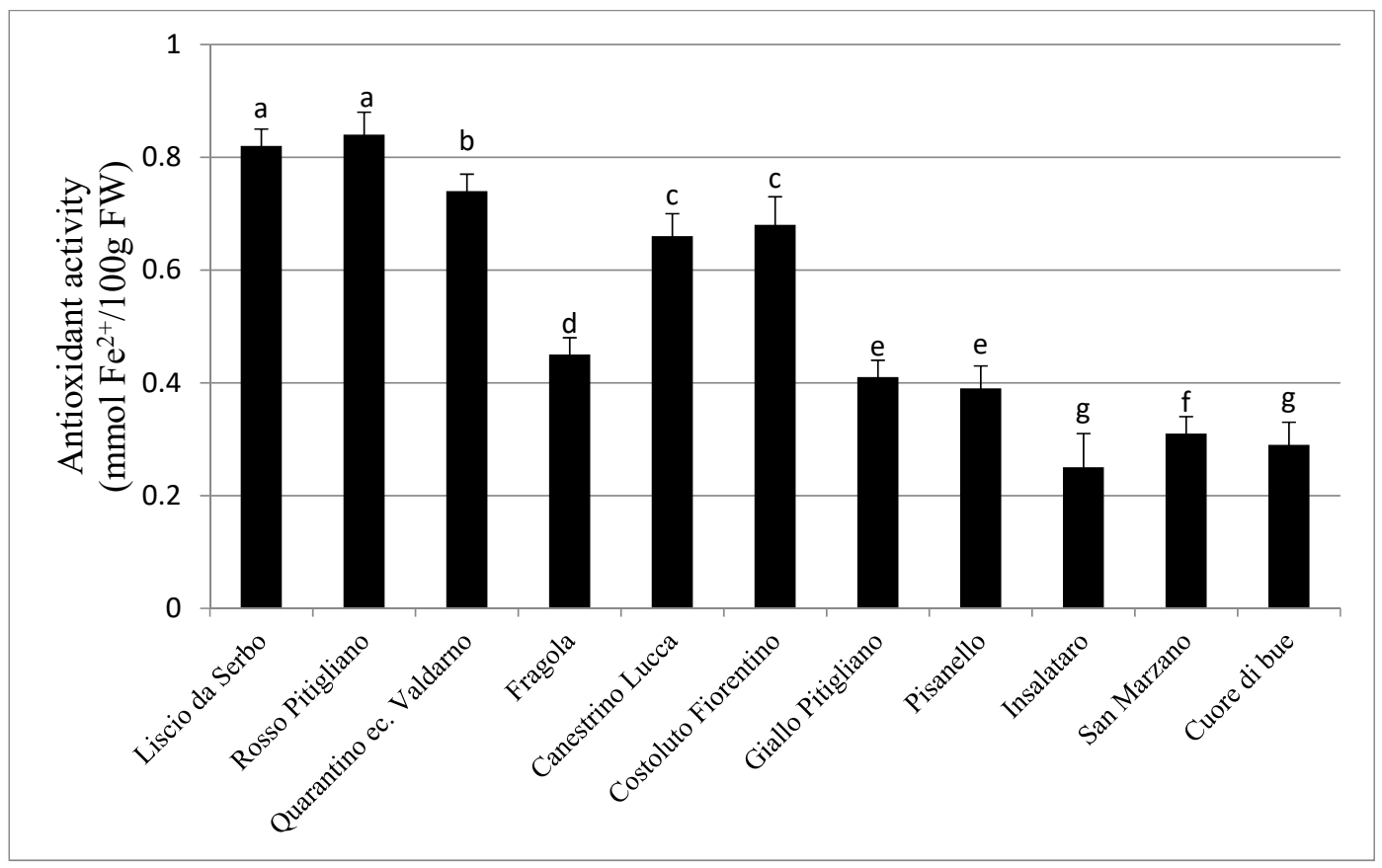

Figure 1. Total content of antioxidant compounds by the Ferric Reducing Antioxidant Power (FRAP) assay for eight ancient and three commercial tomato varieties (left to right) expressed as mmol $\mathrm{Fe}^{2+} / 100 \mathrm{~g}$ FW. Different letters $\left({ }^{\mathrm{a}-\mathrm{g}}\right)$ indicate statistically significant differences at $P<0.05$.

\subsection{Total Phenolic Content}

The highest concentration of polyphenols was in the varieties 'Quarantino ec. Valdarno' and 'Liscio da Serbo Toscano', while 'Canestrino di Lucca' showed the lowest value among the ancient varieties (51.07 mg GAE/100 g FW) (Figure 2). Commercial varieties showed the lowest values: 'Insalataro' 33.30 mg GAE/100 g FW, 'San Marzano' 47.23 mg GAE/100 g FW, and 'Cuore di Bue' $42.31 \mathrm{mg} \mathrm{GAE} / 100 \mathrm{~g}$ FW. To evaluate the contribution of polyphenols to the total antioxidant capacity, the Pearson correlation coefficient was calculated. It indicated a strong positive correlation $(r=0.8335)$. The flavonoid content ranged from $7.82 \mathrm{mg}$ QeE/100 g FW in 'Costoluto Fiorentino' to $13.02 \mathrm{mg}$ QeE/100 g FW in 'Canestrino di Lucca' for the Tuscan varieties (Figure 3). The lowest concentrations of flavonoid compounds were obtained for 'Costoluto Fiorentino' and 'Quarantino ec. Valdarno'. Total flavonoids showed a weak correlation with the antioxidant potential, according to the Pearson correlation coefficient $(r=0.4271)$. The commercial varieties had lower flavonoid contents than the native ones, with values of $6.04 \mathrm{mg}$ QeE/100 $\mathrm{g}$ FW for 'Insalataro', $6.98 \mathrm{mg}$ QeE/100 $\mathrm{g}$ FW for 'San Marzano', and $6.74 \mathrm{mg}$ QeE/100 g FW for 'Cuore di Bue (Figure 3). 


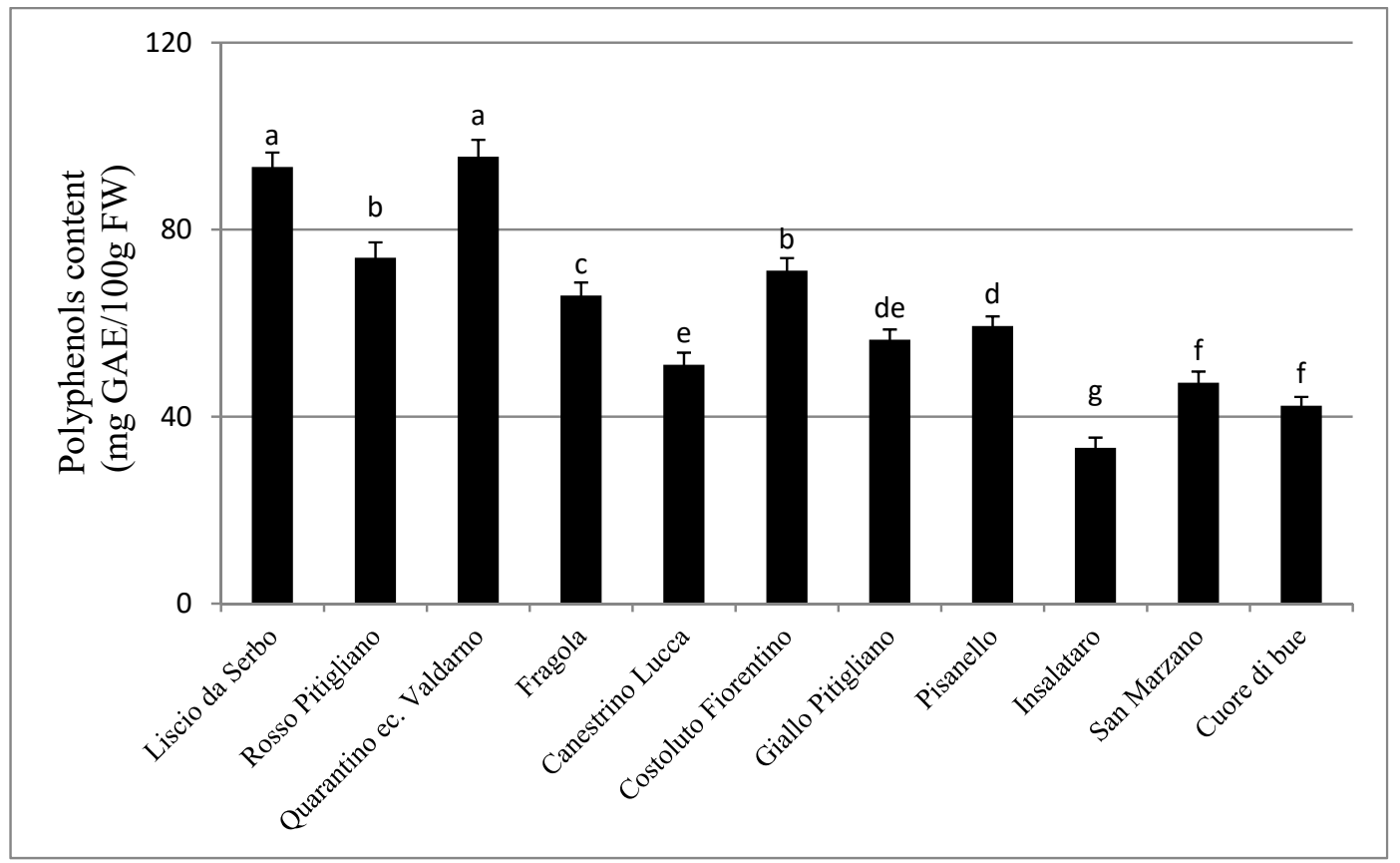

Figure 2. Total extractable polyphenols from the Folin-Ciocalteau assay for eight ancient and three commercial tomato varieties (left to right) expressed in mg Gallic Acid Equivalents (GAE) per $100 \mathrm{~g}$ fresh weight. Different letters $\left.{ }^{\left({ }^{-}-\mathrm{g}\right.}\right)$ refer to statistically significant differences at $P<0.05$.

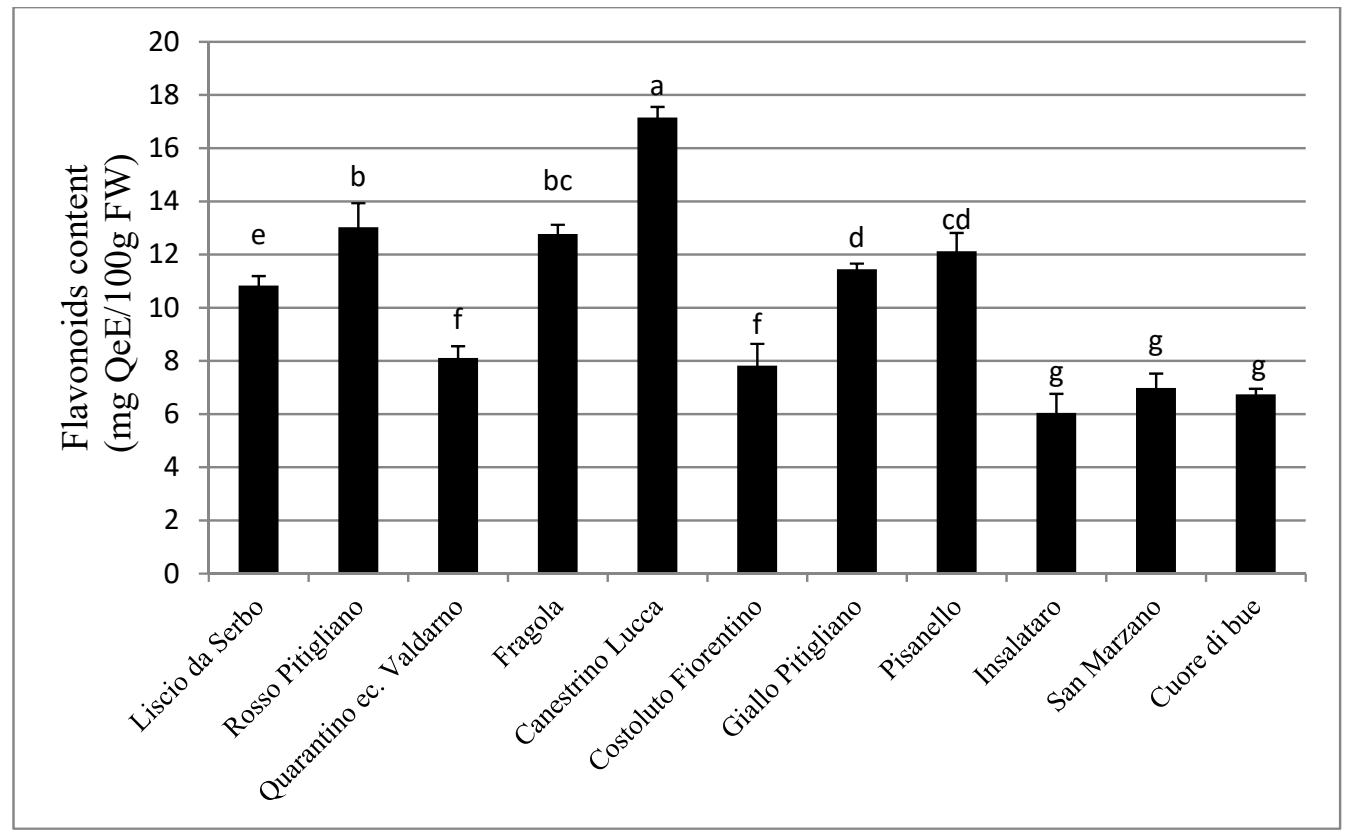

Figure 3. Total flavonoid compounds measured with the aluminum chloride assay of eight ancient and three commercial tomato varieties (left to right) expressed in mg Quercetin Equivalents (QeE) per $100 \mathrm{~g}$ fresh weight. Different letters $\left({ }^{a-g}\right)$ refer to statistically significant differences at $P<0.05$.

\subsection{Carotenoid Content}

The carotenoid values were between $0.88 \mathrm{mg}$ TCC $/ 100 \mathrm{~g}$ FW for 'Canestrino di Lucca' to $0.72 \mathrm{mg}$ mg TCC /100 g FW for 'Costoluto Fiorentino' (Figure 4). Although there were differences in carotenoid content among the ancient varieties, they were not as evident as those reported in previous tests. Comparison of the data obtained for the ancient versus the commercial tomato varieties also showed slight differences in carotenoid content. The Pearson correlation showed a weak positive value between 
carotenoids and total antioxidants $(r=0.3)$. The Lichtenthaler test showed a similar carotenoid content in all cultivars (Figure 4).

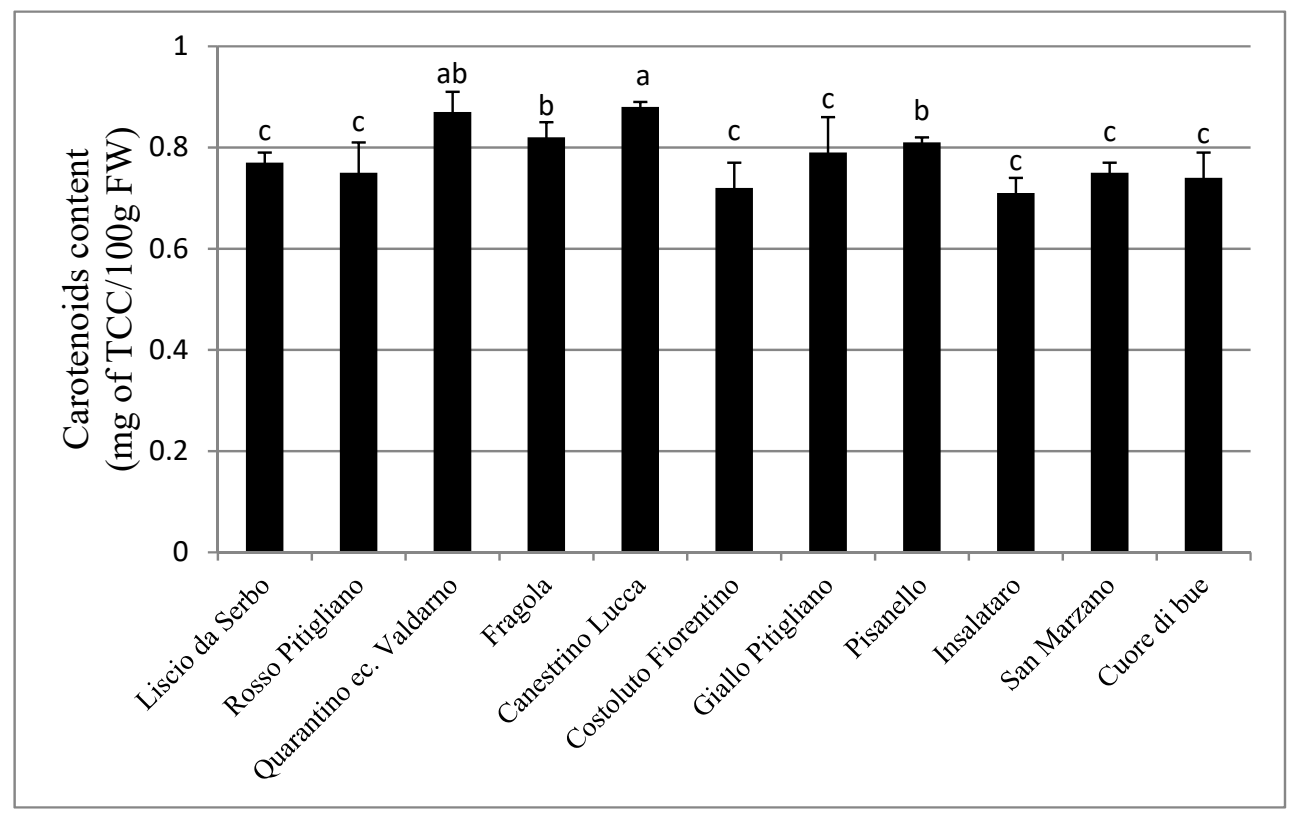

Figure 4. Total carotenoid content (TCC) by the Lichtenthaler assay of eight ancient and three commercial tomato varieties (left to right) expressed as mg TCC $/ 100 \mathrm{~g}$ fresh weight. Different letters $\left({ }^{a-c}\right)$ indicate statistically significant differences at $P<0.05$.

\subsection{Phenolic Profile}

As expected, chlorogenic acid was the main compound found in tomatoes with the highest levels in the 'Liscio da Serbo' Tuscan variety (Table 1). Commercial tomatoes showed the lowest content, and, in the case of the 'Insalataro' variety, half of the average concentration. Chlorogenic acid showed a moderate positive correlation value with total antioxidants $(r=0.7486)$. Caffeic acid was in high amounts in the tomatoes, and it was more concentrated in the 'Rosso di Pitigliano' variety. Caffeic acid was also significantly lower in concentration in the commercial varieties than the ancient cultivars. The Pearson coefficient showed a moderate positive correlation value with the antioxidant power for caffeic acid $(r=0.6394)$. The least represented hydroxycinnamic acid was ferulic acid. The varieties with the highest concentration of this acid were 'Rosso di Pitigliano' and 'Quarantino ec. Valdarno', which had the same concentration, while the commercial cultivars reported the lowest values. Ferulic acid showed a moderate positive correlation with the antioxidant compounds $(r=0.6533)$. The HPLC method showed another class of phenolic compound, represented by flavonoids (quercetin and naringenin). The highest concentration of quercetin was detected in 'Rosso di Pitigliano', while naringenin was at the high concentrations in 'Fragola' and 'Rosso di Pitigliano'. Quercetin and naringenin contents detected in commercial varieties were, in all cases, lower than the locally grown tomatoes. Quercetin and naringenin were evaluated for their antioxidant contribution through the Pearson test. Quercetin showed a strong positive correlation $(r=0.8456)$, while naringenin had a weak positive correlation $(r=0.4199)$. 
Table 1. Content of individual phenolic compounds, vitamin $C$, and lycopene of eight ancient and three commercial tomato varieties (top to bottom). Mean values and relative standard deviations are expressed as $\mathrm{mg}$ of compound per $100 \mathrm{~g}$ fresh weight. Different letters ${ }^{\left({ }^{a}-\mathrm{h}\right.}$ ) refer to statistically significant differences at $P<0.05$.

\begin{tabular}{|c|c|c|c|c|c|c|c|}
\hline Tomato Variety & Chlorogenic Acid & Caffeic Acid & Ferulic Acid & Quercetin & Naringenin & Vitamin C & Lycopene \\
\hline Liscio da Serbo Toscano & $3.51 \pm 0.04^{\mathrm{a}}$ & $1.79 \pm 0.14^{\mathrm{a}}$ & $0.41 \pm 0.07^{\mathrm{d}}$ & $1.52 \pm 0.19^{b}$ & $0.47 \pm 0.04^{\mathrm{e}}$ & $0.30 \pm 0.001^{b}$ & $0.44 \pm 0.07^{\mathrm{d}}$ \\
\hline Rosso di Pitigliano & $2.01 \pm 0.05^{\mathrm{e}}$ & $1.87 \pm 0.13^{\mathrm{a}}$ & $0.96 \pm 0.11^{\mathrm{a}}$ & $2.67 \pm 0.36^{\mathrm{a}}$ & $1.25 \pm 0.15^{\mathrm{a}}$ & $0.34 \pm 0.003^{c}$ & $0.45 \pm 0.03^{\mathrm{d}}$ \\
\hline Quarantino ec. Valdarno & $3.41 \pm 0.03^{\mathrm{a}}$ & $0.78 \pm 0.09^{\mathrm{e}}$ & $0.95 \pm 0.03^{\mathrm{a}}$ & $2.55 \pm 0.28^{\mathrm{a}}$ & $0.43 \pm 0.02^{\mathrm{e}}$ & $0.29 \pm 0.005^{b}$ & $0.59 \pm 0.03^{\mathrm{a}}$ \\
\hline Fragola & $2.52 \pm 0.07^{\mathrm{c}}$ & $0.72 \pm 1.41^{\mathrm{e}}$ & $0.66 \pm 0.07^{c}$ & $1.36 \pm 0.11^{\mathrm{c}}$ & $1.01 \pm 0.12^{b}$ & $0.17 \pm 0.007^{\mathrm{e}}$ & $0.51 \pm 0.04^{c}$ \\
\hline Canestrino di Lucca & $2.14 \pm 0.11^{\mathrm{d}}$ & $0.71 \pm 0.05^{\mathrm{f}}$ & $0.32 \pm 0.01^{\mathrm{e}}$ & $1.68 \pm 0.24^{b}$ & $0.65 \pm 0.07^{c}$ & $0.19 \pm 0.002^{\mathrm{d}}$ & $0.60 \pm 0.01^{\mathrm{a}}$ \\
\hline Costoluto Fiorentino & $2.71 \pm 0.09^{b}$ & $1.17 \pm 0.16^{\mathrm{c}}$ & $0.72 \pm 0.04^{b}$ & $1.27 \pm 0.18^{c}$ & $0.52 \pm 0.06^{\mathrm{d}}$ & $0.18 \pm 0.004^{\mathrm{e}}$ & $0.44 \pm 0.07^{\mathrm{d}}$ \\
\hline Giallo di Pitigliano & $2.01 \pm 0.06^{\mathrm{e}}$ & $0.84 \pm 0.08^{\mathrm{d}}$ & $0.76 \pm 0.11^{b}$ & $0.95 \pm 0.16^{\mathrm{d}}$ & $0.71 \pm 0.04^{c}$ & $0.17 \pm 0.006^{\mathrm{e}}$ & $0.44 \pm 0.04^{\mathrm{d}}$ \\
\hline Pisanello & $1.78 \pm 0.12^{\mathrm{f}}$ & $1.61 \pm 0.18^{b}$ & $0.31 \pm 0.02 \mathrm{e}$ & $0.99 \pm 0.17^{\mathrm{d}}$ & $0.44 \pm 0.06^{\mathrm{e}}$ & $0.22 \pm 0.012^{c}$ & $0.60 \pm 0.04^{\mathrm{a}}$ \\
\hline Insalataro & $1.55 \pm 0.09^{\mathrm{h}}$ & $0.48 \pm 0.06^{h}$ & $0.14 \pm 0.01^{\mathrm{g}}$ & $0.77 \pm 0.19^{\mathrm{e}}$ & $0.33 \pm 0.07^{\mathrm{f}}$ & $0.10 \pm 0.002^{g}$ & $0.42 \pm 0.02 \mathrm{e}$ \\
\hline San Marzano & $1.61 \pm 0.13 \mathrm{~g}$ & $0.63 \pm 0.05^{g}$ & $0.20 \pm 0.01^{\mathrm{f}}$ & $0.72 \pm 0.18^{\mathrm{e}}$ & $0.40 \pm 0.08^{\mathrm{e}}$ & $0.15 \pm 0.009^{f}$ & $0.54 \pm 0.06^{\mathrm{a}}$ \\
\hline Cuore di Bue & $1.58 \pm 0.07^{\mathrm{h}}$ & $0.61 \pm 0.02 \mathrm{~g}$ & $0.19 \pm 0.03^{\mathrm{f}}$ & $0.79 \pm 0.15^{\mathrm{e}}$ & $0.39 \pm 0.05^{\mathrm{e}}$ & $0.11 \pm 0.001^{g}$ & $0.52 \pm 0.05^{b}$ \\
\hline
\end{tabular}




\subsection{Vitamin C Profile}

Vitamin $C$ in the tomato varieties varied (Table 1). There were high concentrations of vitamin $\mathrm{C}$ in 'Liscio da Serbo Toscano', 'Rosso di Pitigliano' and 'Quarantino ec. Valdarno'. The Pearson coefficient showed a strong positive correlation between vitamin $C$ and antioxidant power $(r=0.8737)$. The ancient tomato varieties all showed the higher vitamin $C$ values than the commercial varieties, but high vitamin C levels were also reported in commercial varieties (e.g, 'San Marzano').

\subsection{Lycopene Analysis}

Unlike polyphenol content, lycopene showed a small variation in concentration among the ancient and commercial tomato varieties (Table 1). 'Quarantino ec. Valdarno', 'Pisanello', and 'Canestrino di Lucca' displayed the highest values. In contrast to the other compounds, lycopene showed a negative correlation with total antioxidant power $(r=-0.0568)$.

\section{Discussion}

Ancient plant varieties represent the identity of the Tuscan territory but are threatened by genetic erosion; therefore, it is of fundamental importance to recover and preserve the ancient germplasm to protect biodiversity and local identity [20]. Furthermore, the renewed interest in the consumption of locally grown fruits is also closely linked to the rediscovery of local traditions. In this case, the ancient tomatoes have been evaluated for their nutraceutical properties by characterizing their bioactive compounds. Our case study was prompted by previous characterization of high functional compound contents in ancient species [19,30,31]. The higher levels of bioactives were explained by invoking adaptive strategies developed in the mutualistic relationships between plants and native ecosystems [20]. From a genetic point of view, we highlighted differences in genome and gene expression, thus emphasizing the unique traits of these local plants [32,33]. In this respect, we believe that our research is useful as it quantifies the content of these compounds, with specific attention on antioxidants, polyphenols, flavonoids, and carotenoids in both fruits of ancient and commercial tomatoes.

\subsection{Total Antioxidant Compounds}

The ancient varieties showed high levels of antioxidants. These levels were compared with three of the most consumed tomato varieties in Italy, demonstrating that all Tuscan tomato varieties have a higher content of antioxidant compounds than investigated commercial counterparts. These compounds in ancient varieties were, in the majority of cases, higher compared to those in commercial ones [34,35]. In our specific case study, Tuscan tomatoes showed two- or three-fold higher values of antioxidant concentration.

\subsection{Polyphenols and Flavonoids}

Generally, local tomato varieties showed a higher content of total polyphenols and flavonoids, as demonstrated by the Folin-Ciocalteau and aluminum chloride assays (Figures 2 and 3), respectively. The results were confirmed by HPLC chromatographic analysis (Table 1) which identified the individual components of the various classes of compounds. In tomatoes, we found hydroxycinnamic acids and flavonoids, specifically ferulic acid, caffeic acid, quercetin, and naringenin. Comparing our data with previous reports for other local tomato varieties, the same trends occurred [36,37]. As Ilahy et al. [35] and Kaur et al. [35] reported, locally-grown tomatoes showed a higher content of polyphenols and flavonoids when compared to commercial varieties [34,35]. A Pearson correlation coefficient was calculated to find their eventual contribution to the total antioxidant content. As expected and reported by other authors, moderate and strong correlations were found when phenolic acids (chlorogenic, ferulic, and caffeic acid) were correlated with total antioxidant content, indicating that this class of compounds is crucial in determining the overall antioxidant 
content, e.g., [38,39]. Although quercetin showed a strong positive Pearson correlation coefficient, total flavonoids had a weak correlation with the total antioxidant activity. Teleszko et al. reported similarly correlated values in leaves of particular fruits (cranberry, apple, chokeberry, Japanese quince, bilberry, and blackcurrant leaves), even though these and our data were in disagreement with other published studies $[40,41]$. This may be explained by considering the low correlation coefficient calculated for naringenin, which is present in high concentrations in tomatoes [42,43].

\subsection{Carotenoids and Vitamin C}

Tomatoes are an excellent source of carotenoids, like lycopene [44]. The tomato is also one of the richest sources of vitamin $C$ and its consumption is recommended for the daily intake of ascorbic acid [45]. As for the carotenoid content, there were no significant differences between ancient and commercial varieties (Figure 4). In contrast, differences were evident in the content of Vitamin C present in ancient varieties (Table 1). These two classes of compounds were at lower quantities in the Tuscan tomatoes investigated here, while compared with six other Italian tomato varieties investigated by other authors, that displayed higher carotenoid contents [34,35]. Although these results partially disagree with our data, it should be considered that the content of bioactive compounds is determined by the synergy of different factors, namely genotype, seasonality, original territory, agronomic treatments, and ripening time [46,47]. This finding can be explained in light of the selection criterion driven by specific features of fruit shape and color. A weak positive correlation was also found between carotenoids and antioxidant content. It should be noted that the most represented carotenoid in tomato, lycopene, showed a negative correlation with total antioxidants and may, therefore, be responsible for the overall low correlation measured for total carotenoids. Contrary to the Pearson correlation value for lycopene, vitamin $C$ showed a high positive correlation with total antioxidants, witnessing their contribution on the total antioxidant potential of the tomato fruits.

Overall, our results showed a higher contribution to the total antioxidant content of phenolic acids and vitamin C, compared to flavonoids and carotenoids, in tomato fruits. Future studies focusing on the relationship between specific chemical structures and total antioxidant content and on the synergy of different classes of compounds will elucidate the impact of the different classes of bioactives in ancient tomatoes. Tomato fruits produce quantities of secondary metabolites depending on various factors such as agronomic treatment, geographical production areas, and variety. Therefore, it is necessary to understand whether a relationship between these factors and the total antioxidant capacity of the fruit exists in order to fully exploit the potential health benefits deriving from the consumption of these fruits [48].

\section{Conclusions}

The antioxidant, polyphenol, flavonoid, carotenoid, and vitamin C contents were evaluated in Tuscan tomato varieties and compared to commercial ones. Our study was carried out by combining chemical assays with HPLC analyses. The results showed the high contents in functional compounds in Tuscan local tomatoes that were, in the majority of the cases, greater than those found in commercial varieties. Therefore, these data confirm the intrinsic value of ancient varieties as alternatives, in terms of nutraceutical content, to commercial cultivars. These ancient varieties may have the potential to satisfy the increasing demand for food products with higher contents of nutraceutical compounds. On a longer-term perspective, the valorization of local species can foster, at a regional level, the commercialization of new "niche products" derived from ancient fruits. Our study will also pave the way for future studies focusing on the relationship between seasonality and the content of functional compounds. In this respect, plant epigenomics is expected to provide crucial information.

Author Contributions: Funding acquisition, M.R. and C.C.; Methodology, R.B.; Project administration, M.R., G.C. and C.C.; Supervision, G.C. and C.C.; Writing—original draft, R.B.; Writing-review \& editing, L.P. and G.C. 
Funding: This work was supported by Tuscany in the framework of PSR (Progetto Sviluppo Rurale) 2014-2020.

Acknowledgments: The authors wish to thank the Tuscany Region and the national research council (CNR-Italy) for supporting this research and making available the plant material. This work was carried out in the context of the "Mangiare corto per guardare lontano" (BASIQ) project, measure for the technological transfer 16.2.

Conflicts of Interest: The authors declare no conflict of interest.

\section{References}

1. Alissa, E.M.; Ferns, G.A. Functional foods and nutraceuticals in the primary prevention of cardiovascular diseases. J. Nutr. Metab. 2012, 2012, 569486. [CrossRef] [PubMed]

2. Guerriero, G.; Berni, R.; Muñoz-Sanchez, J.; Apone, F.; Abdel-Salam, E.; Qahtan, A.; Alatar, A.; Cantini, C.; Cai, G.; Hausman, J.-F. Production of plant secondary metabolites: Examples, tips and suggestions for biotechnologists. Genes 2018, 9, 309. [CrossRef] [PubMed]

3. Vauzour, D. Dietary polyphenols as modulators of brain functions: Biological actions and molecular mechanisms underpinning their beneficial effects. Oxid. Med. Cell. Longev. 2012, 2012, 941273. [CrossRef] [PubMed]

4. Shahidi, F.; Ambigaipalan, P. Phenolics and polyphenolics in foods, beverages and spices: Antioxidant activity and health effects-A review. J. Funct. Foods 2015, 18, 820-897. [CrossRef]

5. Agati, G.; Azzarello, E.; Pollastri, S.; Tattini, M. Flavonoids as antioxidants in plants: Location and functional significance. Plant Sci. 2012, 196, 67-76. [CrossRef] [PubMed]

6. Rozenberg, S.; Body, J.-J.; Bruyère, O.; Bergmann, P.; Brandi, M.L.; Cooper, C.; Devogelaer, J.-P.; Gielen, E.; Goemaere, S.; Kaufman, J.-M. Effects of dairy products consumption on health: Benefits and beliefsA commentary from the Belgian Bone Club and the European Society for Clinical and Economic Aspects of Osteoporosis, Osteoarthritis and Musculoskeletal Diseases. Calcif. Tissue Int. 2016, 98, 1-17. [CrossRef] [PubMed]

7. Russo, M.; Spagnuolo, C.; Tedesco, I.; Bilotto, S.; Russo, G.L. The flavonoid quercetin in disease prevention and therapy: Facts and fancies. Biochem. Pharmacol. 2012, 83, 6-15. [CrossRef] [PubMed]

8. Scalbert, A.; Manach, C.; Morand, C.; Rémésy, C.; Jiménez, L. Dietary polyphenols and the prevention of diseases. Crit. Rev. Food Sci. Nutr. 2005, 45, 287-306. [CrossRef] [PubMed]

9. Han, X.; Shen, T.; Lou, H. Dietary polyphenols and their biological significance. Int. J. Mol. Sci. 2007, 8, 950-988. [CrossRef]

10. Meydan, D.; Gursel, B.; Bilgici, B.; Can, B.; Ozbek, N. Protective effect of lycopene against radiation-induced hepatic toxicity in rats. J. Int. Med. Res. 2011, 39, 1239-1252. [CrossRef] [PubMed]

11. Agarwal, S.; Rao, A.V. Tomato lycopene and its role in human health and chronic diseases. Can. Med. Assoc. J. 2000, 163, 739-744.

12. Martínez-Valverde, I.; Periago, M.J.; Provan, G.; Chesson, A. Phenolic compounds, lycopene and antioxidant activity in commercial varieties of tomato (Lycopersicum esculentum). J. Sci. Food Agric. 2002, 82, 323-330. [CrossRef]

13. Hamid, A.A.; Aiyelaagbe, O.O.; Usman, L.A.; Ameen, O.M.; Lawal, A. Antioxidants: Its medicinal and pharmacological applications. Afr. J. Pure Appl. Chem. 2010, 4, 142-151.

14. Firuzi, O.; Miri, R.; Tavakkoli, M.; Saso, L. Antioxidant therapy: Current status and future prospects. Curr. Med. Chem. 2011, 18, 3871-3888. [CrossRef] [PubMed]

15. Canene-Adams, K.; Campbell, J.K.; Zaripheh, S.; Jeffery, E.H.; Erdman, J.W. The tomato as a functional food. J. Nutr. 2005, 135, 1226-1230. [CrossRef] [PubMed]

16. Pirillo, A.; Catapano, A.L. NUTRACEUTICA: DEFINIZIONE, REGOLAMENTAZIONE E APPLICAZIONI Nutraceuticals: Definitions, European regulations and clinical applications. G. Ital. Farm. Farm. 2014, 6, 23-30.

17. Bita, C.; Gerats, T. Plant tolerance to high temperature in a changing environment: Scientific fundamentals and production of heat stress-tolerant crops. Front. Plant Sci. 2013, 4, 273. [CrossRef] [PubMed]

18. Guo, J.; Yue, T.; Yuan, Y.; Wang, Y. Chemometric classification of apple juices according to variety and geographical origin based on polyphenolic profiles. J. Agric. Food Chem. 2013, 61, 6949-6963. [CrossRef] [PubMed] 
19. Iacopini, P.; Camangi, F.; Stefani, A.; Sebastiani, L. Antiradical potential of ancient Italian apple varieties of Malus x domestica Borkh. in a peroxynitrite-induced oxidative process. J. Food Compos. Anal. 2010, 23, 518-524. [CrossRef]

20. Berni, R.; Cantini, C.; Romi, M.; Hausman, J.-F.; Guerriero, G.; Cai, G. Agrobiotechnology Goes Wild: Ancient Local Varieties as Sources of Bioactives. Int. J. Mol. Sci. 2018, 19, 2248. [CrossRef] [PubMed]

21. Henríquez, C.; Almonacid, S.; Chiffelle, I.; Valenzuela, T.; Araya, M.; Cabezas, L.; Simpson, R.; Speisky, H. Determination of antioxidant capacity, total phenolic content and mineral composition of different fruit tissue of five apple cultivars grown in Chile. Chil. J. Agric. Res. 2010, 70, 523-536. [CrossRef]

22. Benzie, I.F.; Strain, J.J. The ferric reducing ability of plasma (FRAP) as a measure of "antioxidant content": The FRAP assay. Anal. Biochem. 1996, 239, 70-76. [CrossRef] [PubMed]

23. Singleton, V.L.; Rossi, J.A. Colorimetry of total phenolics with phosphomolybdic-phosphotungstic acid reagents. Am. J. Enol. Vitic. 1965, 16, 144-158.

24. Ebrahimzadeh, M.A.; Pourmorad, F.; Hafezi, S. Antioxidant activities of Iranian corn silk. Turk. J. Biol. 2008, $32,43-49$.

25. Lichtenthaler, H.K.; Wellburn, A.R. Determinations of Total Carotenoids and Chlorophylls a and b of Leaf Extracts in Different Solvents. Biochem. Soc. Trans. 1983, 11, 591-592. [CrossRef]

26. Tokuşoğlu, Ö.; Ünal, M.K.; Yıldırım, Z. HPLC-UV and GC-MS characterization of the flavonol aglycons quercetin, kaempferol, and myricetin in tomato pastes and other tomato-based products. Acta Chromatogr. 2003, 13, 196-207.

27. Kumar, N.; Bhandari, P.; Singh, B.; Gupta, A.P.; Kaul, V.K. Reversed phase-HPLC for rapid determination of polyphenols in flowers of rose species. J. Sep. Sci. 2008, 31, 262-267. [CrossRef] [PubMed]

28. Barba, A.O.; Hurtado, M.C.; Mata, M.S.; Ruiz, V.F.; De Tejada, M.L.S. Application of a UV-vis detection-HPLC method for a rapid determination of lycopene and $\beta$-carotene in vegetables. Food Chem. 2006, 95, 328-336. [CrossRef]

29. Scherer, R.; Rybka, A.C.P.; Ballus, C.A.; Meinhart, A.D.; Teixeira Filho, J.; Godoy, H.T. Validation of a HPLC method for simultaneous determination of main organic acids in fruits and juices. Food Chem. 2012, 135, 150-154. [CrossRef]

30. Ancillotti, C.; Ciofi, L.; Pucci, D.; Sagona, E.; Giordani, E.; Biricolti, S.; Gori, M.; Petrucci, W.A.; Giardi, F.; Bartoletti, R. Polyphenolic profiles and antioxidant and antiradical activity of Italian berries from Vaccinium myrtillus L. and Vaccinium uliginosum L. subsp. gaultherioides (Bigelow) SB Young. Food Chem. 2016, 204, 176-184. [CrossRef] [PubMed]

31. Mirto, A.; Iannuzzi, F.; Carillo, P.; Ciarmiello, L.F.; Woodrow, P.; Fuggi, A. Metabolic characterization and antioxidant activity in sweet cherry (Prunus avium L.) Campania accessions: Metabolic characterization of sweet cherry accessions. Food Chem. 2018, 240, 559-566. [CrossRef] [PubMed]

32. Legay, S.; Guerriero, G.; Deleruelle, A.; Lateur, M.; Evers, D.; André, C.M.; Hausman, J.-F. Apple russeting as seen through the RNA-seq lens: Strong alterations in the exocarp cell wall. Plant Mol. Biol. 2015, 88, 21-40. [CrossRef] [PubMed]

33. Legay, S.; Cocco, E.; André, C.M.; Guignard, C.; Hausman, J.-F.; Guerriero, G. Differential Lipid Composition and Gene Expression in the Semi-Russeted “Cox Orange Pippin” Apple Variety. Front. Plant Sci. 2017, 8. [CrossRef] [PubMed]

34. Ilahy, R.; Hdider, C.; Lenucci, M.S.; Tlili, I.; Dalessandro, G. Phytochemical composition and antioxidant activity of high-lycopene tomato (Solanum lycopersicum L.) cultivars grown in Southern Italy. Sci. Hortic. 2011, 127, 255-261. [CrossRef]

35. Kaur, C.; Walia, S.; Nagal, S.; Walia, S.; Singh, J.; Singh, B.B.; Saha, S.; Singh, B.; Kalia, P.; Jaggi, S. Functional quality and antioxidant composition of selected tomato (Solanum lycopersicon L) cultivars grown in Northern India. LWT-Food Sci. Technol. 2013, 50, 139-145. [CrossRef]

36. George, B.; Kaur, C.; Khurdiya, D.S.; Kapoor, H.C. Antioxidants in tomato (Lycopersium esculentum) as a function of genotype. Food Chem. 2004, 84, 45-51. [CrossRef]

37. Toor, R.K.; Savage, G.P. Antioxidant activity in different fractions of tomatoes. Food Res. Int. 2005, 38, 487-494. [CrossRef]

38. Bertoncelj, J.; Doberšek, U.; Jamnik, M.; Golob, T. Evaluation of the phenolic content, antioxidant activity and colour of Slovenian honey. Food Chem. 2007, 105, 822-828. [CrossRef] 
39. Du, G.; Li, M.; Ma, F.; Liang, D. Antioxidant capacity and the relationship with polyphenol and vitamin C in Actinidia fruits. Food Chem. 2009, 113, 557-562. [CrossRef]

40. Teleszko, M.; Wojdyło, A. Comparison of phenolic compounds and antioxidant potential between selected edible fruits and their leaves. J. Funct. Foods 2015, 14, 736-746. [CrossRef]

41. Mustafa, R.A.; Hamid, A.A.; Mohamed, S.; Bakar, F.A. Total phenolic compounds, flavonoids, and radical scavenging activity of 21 selected tropical plants. J. Food Sci. 2010, 75, C28-C35. [CrossRef] [PubMed]

42. Rice-Evans, C.; Miller, N.; Paganga, G. Antioxidant properties of phenolic compounds. Trends Plant Sci. 1997, 2, 152-159. [CrossRef]

43. Leopoldini, M.; Russo, N.; Toscano, M. The molecular basis of working mechanism of natural polyphenolic antioxidants. Food Chem. 2011, 125, 288-306. [CrossRef]

44. Abushita, A.A.; Daood, H.G.; Biacs, P.A. Change in carotenoids and antioxidant vitamins in tomato as a function of varietal and technological factors. J. Agric. Food Chem. 2000, 48, 2075-2081. [CrossRef] [PubMed]

45. Fitzpatrick, T.B.; Basset, G.J.; Borel, P.; Carrari, F.; DellaPenna, D.; Fraser, P.D.; Hellmann, H.; Osorio, S.; Rothan, C.; Valpuesta, V. Vitamin deficiencies in humans: Can plant science help? Plant Cell 2012, 24, $395-414$. [CrossRef] [PubMed]

46. Ilahy, R.; Hdider, C.; Lenucci, M.S.; Tlili, I.; Dalessandro, G. Antioxidant activity and bioactive compound changes during fruit ripening of high-lycopene tomato cultivars. J. Food Compos. Anal. 2011, 24, 588-595. [CrossRef]

47. Ibitoye, D.O.; Akin-Idowu, P.E.; Ademoyegun, O.T. Agronomic and lycopene evaluation in tomato (Lycopersicon lycopersicum Mill.) as a function of genotype. World J. Agric. Sci. 2009, 5, 892-895.

48. Viuda-Martos, M.; Sanchez-Zapata, E.; Sayas-Barberá, E.; Sendra, E.; Perez-Alvarez, J.A.; Fernández-López, J. Tomato and tomato byproducts. Human health benefits of lycopene and its application to meat products: A review. Crit. Rev. Food Sci. Nutr. 2014, 54, 1032-1049. [CrossRef] [PubMed] 